\title{
High-dose therapy and autologous hematopoietic progenitor cells transplantation for relapsed or refractory hodgkin lymphoma: a follow up analysis of king hussein cancer center,results and prognostic variables
}

Halahleh Khalid*, Dahabreh Laith, Manasrah Mohamad, Sarrawi Tahani, Rihani Rawad, Ma'koseh Mohammad, Abu Jazar Husam, Abdelghani Tbakhi and Sarhan Mahmoud

King Hussein Cancer Center,Amman, Jordan

\begin{abstract}
Introduction: High dose chemotherapy and autologous stem cell transplantation is a standard of care for patients with relapsed refractory Hodgkin's Lymphoma. Several factors including number of chemotherapy lines received before conditioning, time of relapse and remission status before transplantation can predict overall survival (OS) and progression free survival (PFS) in patients undergoing autologous stem cell transplantation.Abdel-Rahman et alreported on 63 patients, who underwent high dose chemotherapy followed by autologous stem cell transplantation at KHCC from 2003 to 2008. Here in , we report on the outcome of 86 patients, who underwent high dose chemotherapy and autologous $\mathrm{HCT}$ at single institution.

Patients and methods: Patients with relapsed and/or refractory Hodgkin's Lymphoma, Jan,2009-Dec,2016, who underwent high dose chemotherapy and autologous stem cell transplantation were retrospectively analyzed. The primary end points were complete remission (CR) at day 100, progression free survival (PFS0, overall survival (OS) and the impact of the following variables on overall survival and progression free survival: (a) disease status at the time of transplant, (b) number of chemotherapy lines prior to conditioning, (c) time of relapse $<12$ or $>12$ months, (d) age group was also investigated. Secondary end points are day 100 nonrelapse mortality (NRM) and incidence of grade 3-4 mucositis.

Results: $50 \%$ of patients were in complete remission at the time of transplantation and $69.2 \%$ achieved complete remission at day 100. Median overall survival was not reached and an estimated 5-year overall survival 68.8\% \pm 5.9\%, (95\% confidence interval [CI], 55.6, 78.8\%). Median PFS 10.6 months and an estimated 5-year progression free survival rate $51.1 \% \pm 6.58 \%$ ( $95 \%$ confidence interval $[\mathrm{CI}], 37.6,63 \%)$. None of the variables studied was significant for survival outcomes .There is a trend toward improved event free survival in those, who received 2 or less lines of chemotherapy.Unexpectidly, male gender was the only significant factor for improved overall survival, progression free survival and event free survival. TRM is $2.7 \%$ and mucositis occurred in $53 \%$ of patients.
\end{abstract}

Conclusion: The outcome of relapsed refractory HL is favorable and comparable with worldwide reported outcomes. None of the variables studies was significant for survival outcomes. Two or less salvage chemotherapy lines showed a trend toward improved progression free survival.

\section{Introduction}

Hodgkin's lymphoma (HL) is a potentially curable disease with standard chemotherapy combinations. Among patients with earlystage Hodgkin's Lymphoma (HL) the rate of relapse ranges from 10$15 \%$ [1] and in patients with advanced stage $\mathrm{HL}$, the relapse rate ranges from $30-40 \%$ [2-6].In addition, approximately $10-15 \%$ of patients experience progression of disease after an initial partial response. Although no overall survival (OS) benefit has ever been demonstrated in a prospective, randomized clinical trial, salvage chemotherapy followed by high-dose chemotherapy and autologous hematopoetic cell transplantation (HDT-ASCT) is the treatment of choice for patients with chemosensitive refractory or relapsed HL and currently considered the standard of care [7-19].

Several factors can predict survival outcomes after high dose chemotherapy and autologous transplant, including the number of chemotherapy lines received prior to transplant, time to relapse, disease status at the time of transplant, which predicts the risk of relapse in previous studies with superior outcomes in patients transplanted, while in complete remission (CR) and the time to initial relapse (TTR) $<12$ months versus $>12$ months, which is measured from the date of diagnosis to that of proven relapse have also been shown to influence the outcome [20-22].

There was a significant research in the last few years has focused on maximizing outcomes with HDT-ASCT focusing on identification of prognostic factors at relapse, the incorporation of functional imaging (FI) and biomarkers to improve patient selection and timing of HDT-ASCT, the development of novel salvage chemotherapy and conditioning regimens prior to autologous hematopoetic cell

${ }^{\star}$ Correspondence to: Halahleh Khalid, King Hussein Cancer Center, P.O. Box 1269 Al-Jubeiha, Amman 11941, Jordan, Tel: 00972598511670; E-mail: kh.06314@khcc.jo

Key words: hodgkin's lymphoma, hematopoietic progenitor cells, transplantation, cancer

Received: July 05, 2018; Accepted: July 13, 2018; Published: July 16, 2018 
Khalid H (2018) High-dose therapy and autologous hematopoietic progenitor cells transplantation for relapsed or refractory hodgkin lymphoma: a follow up analysis of king hussein cancer center,results and prognostic variables

transplantation, and the first trial tested maintenance therapy after autologous HCT had been published [23-26].

At King Hussein Cancer Center (KHCC) bone marrow transplantation program,we previously reported on 63 patients, who were transplanted between 2003-2008 .Here in ,we report on the outcomes of 86 patients with HL, who were transplanted between 2009-2016. Since our program is combined of adult and pediatric patients, we included the comparison between the two age groups in treatment outcomes. To our knowledge there is no data available on the impact of age on transplantation outcome of Hodgkin's Lymphoma except published report by our group (Adult patients at our center are defined as 18 years or older).

\section{Patients and methods}

We retrospectively analyzed the outcome 86 consecutive subjects with chemo-sensitive relapsed or refractory Hodgkin's lymphoma received an autotransplant in the Department of Hematology and Oncology, King Hussein Cancer Center (KHCC), January, 2009-January, 2016. Written informed consent and IRB-approval were obtained. Diagnosis was confirmed by pathology review. Subject-, disease- and transplant-related variables are shown in the Table 1. Disease evaluation was carried out on day 30 and day 100 posttransplant using PETCT and/or CAT scans using RECIST response criteria $[27,28]$.

\section{Treatment}

Prior to conditioning regimen, $43 \%$ received two lines of salvage chemotherapy. Chemotherapy and GCSF mobilization followed by stem cell collection was used in $94 \%$, while GCSF alone was used only in $6 \%$ of patients.Peripheral blood was the graft source in all patients.94\% received BEAM (BCNU, Etoposide, Ara-c and Melphalan) conditioning, $4.6 \%$ received TEAM (Thiotepa, Etoposide, Ara-C, andMelphalan) and $1.4 \%$ received BEA (BCNU, Etoposide, Arac). Median CD34 positive cell dose delivered was $5.1 \pm 1.6 \mathrm{E}+6$ (SD). All patients received antiviral, antifungal and antibacterial prophylaxis.

\section{Statistical analysis}

The primary end points were the rate of complete remission (CR) on day 100,overall survival ,progression free survival (PFS) and Overall survival (OS), progression free survival (RFS) according to disease status at the time of transplant, number of chemotherapy

Table 1. Subject-, disease- and transplant-related variables

\begin{tabular}{|l|l|l|}
\hline \multirow{2}{*}{ Gender } & M & $46(53.2 \%)$ \\
\cline { 2 - 3 } & F & $42(48.8 \%)$ \\
\hline \multirow{2}{*}{ N. of Chem. cycles } & Adult & $74(86.0 \%)$ \\
\cline { 2 - 3 } Disease status at ABMT & Pediatric & $12(14 \%)$ \\
\hline \multirow{2}{*}{ TTR } & CR & $36(42.0 \%)$ \\
& PR & $50(58.0 \%)$ \\
\hline \multirow{2}{*}{ Mobilization regimen } & $<12$ months & $43(50.0 \%)$ \\
& $>12$ months & $43(50.0 \%)$ \\
\hline Stem cell source & Chem+GCSF & $46(53.5 \%)$ \\
\hline Stem cell dose & GCSF & $40(46.5 \%)$ \\
\hline \multirow{2}{*}{ Conditioning } & Peripheral & $81(94 \%)$ \\
\hline & median & $5(6 \%)$ \\
\hline & BEAM & $100 \%$ \\
\hline & TEAM & $5.1 \pm 1.6 \mathrm{E} 06 / \mathrm{kg}$ \\
\hline & BEA & $84(92.0 \%)$ \\
\hline
\end{tabular}

lines, age group and time to tumor progression (TTR). Secondary end points were transplant-related mortality at day 100 (TRM) and grade III-IV mucositis.Outcomes comparison between groups categorized by disease status at the end of treatment, number of chemotherapy lines received and age group was carried out. Kaplan- Meier method was used to present survival curves. Comparison between groups in survival was carried out using Log Rank test.

\section{Results}

All subjects had rapid bone marrow recovery. Median followup of survivors was 37.4 months (range: 1.12, 98.7mo). Complete remission at day 100 was $69.2 \%$.Median survival was not reached and an estimated 5-year survival was $68.8 \% \pm 5.9 \%$, (95\% confidence interval [CI], 55.6, 78.8\%), Figure 1. PFS was 10.5 months. and 5-year progression free survival was $51.1 \% \pm 6.58 \%$ ( $95 \%$ confidence interval $[\mathrm{CI}], 37.6,63 \%)$. At last encounter, 50 (58.1\%) patients continue to be relapse free and $36(41.9 \%)$ relapsed.Only 2 patients died in the first 100 days post transplant, representing $2.7 \%$ of our cohort. Causes of death were sepsis and respiratory failure-ARDS. This is comparable with international Figures of 3-5\% as for mucositis, it is occurrence reached $53 \%$.

\section{Discussion}

High dose chemotherapy with autologous hematopoetic cell transplantation is an established potentially curative therapy for relapsed/refractory Hodgkin's Lymphoma. Of 86 patients received high-dose chemotherapy and autologous HCT in the study period, $50 \%$ were in complete remission compared with $25 \%$ reported previously with comparable 100 day complete remission rates in both study periods $69.2 \%, 57 \%$ respectively. This supports the notion that complete remission is not prerequisite to proceed to HCT and having a chemo-sensitive disease is a relevant factor.

The median survival for the whole group was not reached with estimated 5-year survival of $68.8 \% \pm 5.9 \%$ compared to median survival of 40.6 months and projected 3-year overall survival of $64.6 \%$.Median PFS 10.6 months with 5-year progression free survival of $51.1 \% \pm 6.58 \%$ compared to 20 months and projected 3 -year PFS of $42.3 \%$ in those reported previously.Also, these survival outcomes were comparable with the results published in a study by Engelhardt, et al. [15] .There was no statistically significant difference in neither overall survival nor progression free survival (PFS) in regard to number of chemotherapy lines received before conditioning, remission status, time to relapse (TTR), age, conditioning regimen (Figure 2). There is only a trend toward improved EFS in those who received less than two lines of salvage chemotherapy before conditioning. Unexpectedly, male gender was the only significant factor for improved survival outcomes, which can be related to small sample size (Figure 3). This concurs with study published by Engelhardt, et al. [15] and contradicts most of previously published series [20-22].

Historically, the outcome is better for patients with chemo-sensitive relapse which concur with our study and those whose duration of first remission has been relatively long that contradicts our findings. This is probably related to small sample size. Also, we transplanted all patients with chemo-sensitive disease and having complete remission is not prerequisite to transplant. This supports the hypothesis that the tumor biology is the most important predictor for OS, with tumors that were sensitive to the first line salvage chemotherapy having a better outcome than those, who were not, even if the latter responded to further salvage chemotherapy. The correlation of male gender with improved survival 


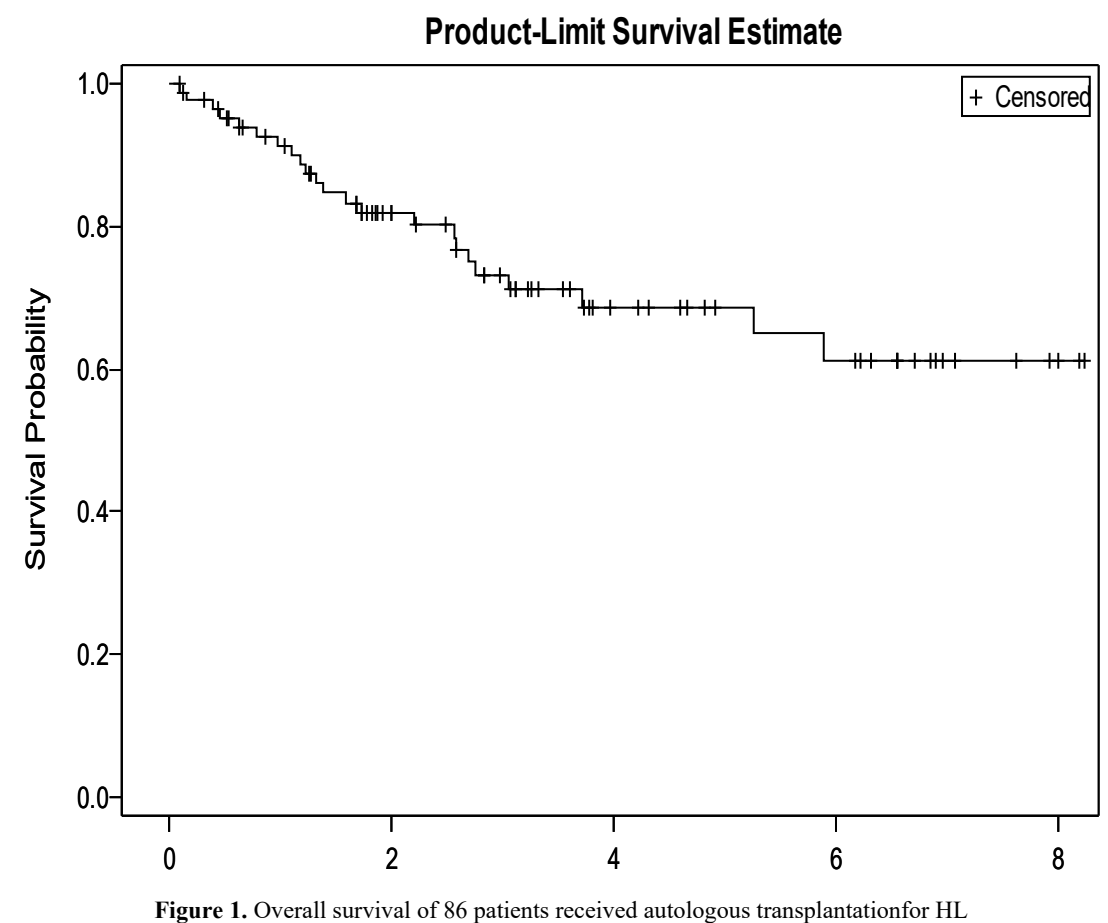

Figure 1. Overall survival of 86 patients received autologous transplantationfor HL

Kaplan-Meier Plot

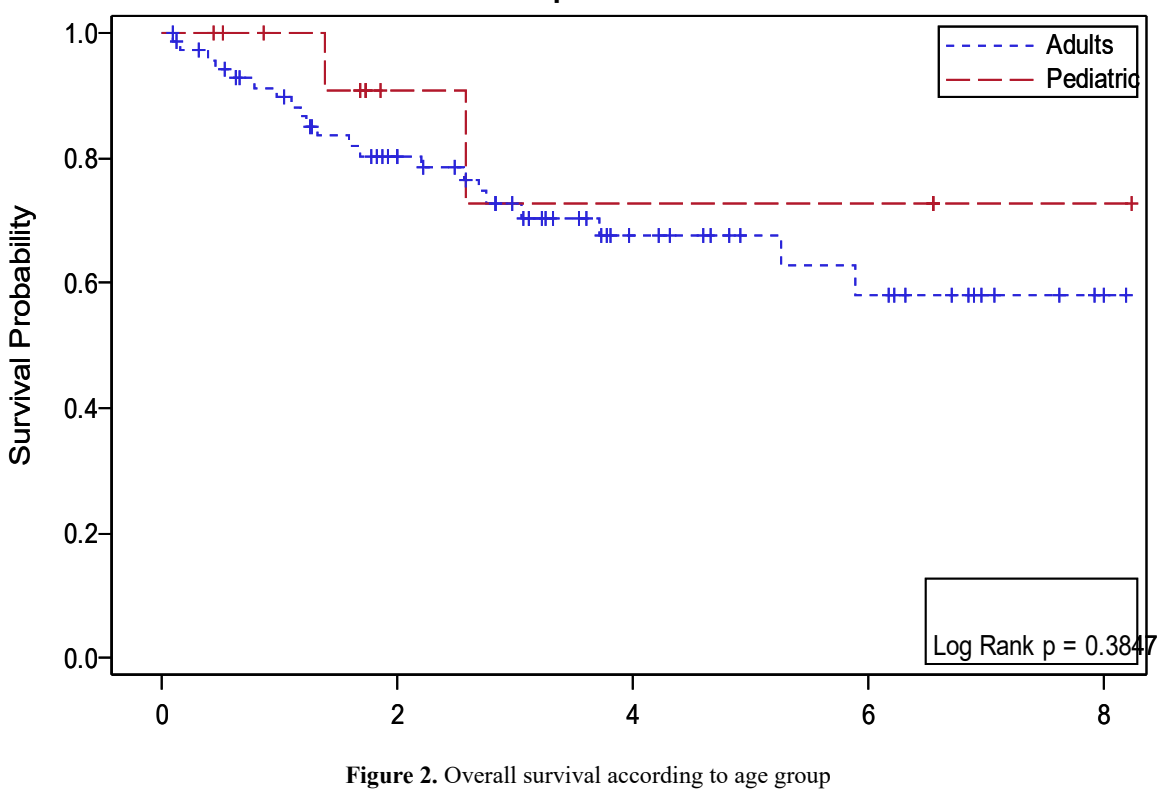

outcomes cannot be explained in our series and we think this might be related to sampling bias. Relapse after autologous hematopoetic cell transplant for Hodgkin's Lymphoma remains a significant problem with $41.9 \%$ of patients relapsed as projected from our study. Large studies have suggested that early relapse, chemotherapy-refractory disease, and the presence of extranodal disease are all clinical factors associated with a high risk for relapse after autologous HCT. It is important to focus on treatment strategies after relapse. There is a potential durable response with reduced intensity allogeneic transplant for HL patients relapsed after autologous transplant as shown in study of Peggs, et al. [23]. Also the use of novel agents like Brentuximab vedotin and PD-1 inhibitors, which were tested in phase III trials have shown promising results showing high response rate reaching $75 \%$ in relapsed/refractory HL and being used as bridging to reducedintensity allogeneic hematopoetic cell transplantation and proved to be of benefit as maintenance post high dose and autologous HCT for high risk HL patients with residual disease as shown in Aethera trial by Seureda, et al. [23-26,29-31].

\section{Conclusion}

We can therefore conclude from our study that the outcome of relapsed refractory $\mathrm{HL}$ is favorable and none of the variables studies was 
Khalid H (2018) High-dose therapy and autologous hematopoietic progenitor cells transplantation for relapsed or refractory hodgkin lymphoma: a follow up analysis of king hussein cancer center,results and prognostic variables

Kaplan-Meier Plo

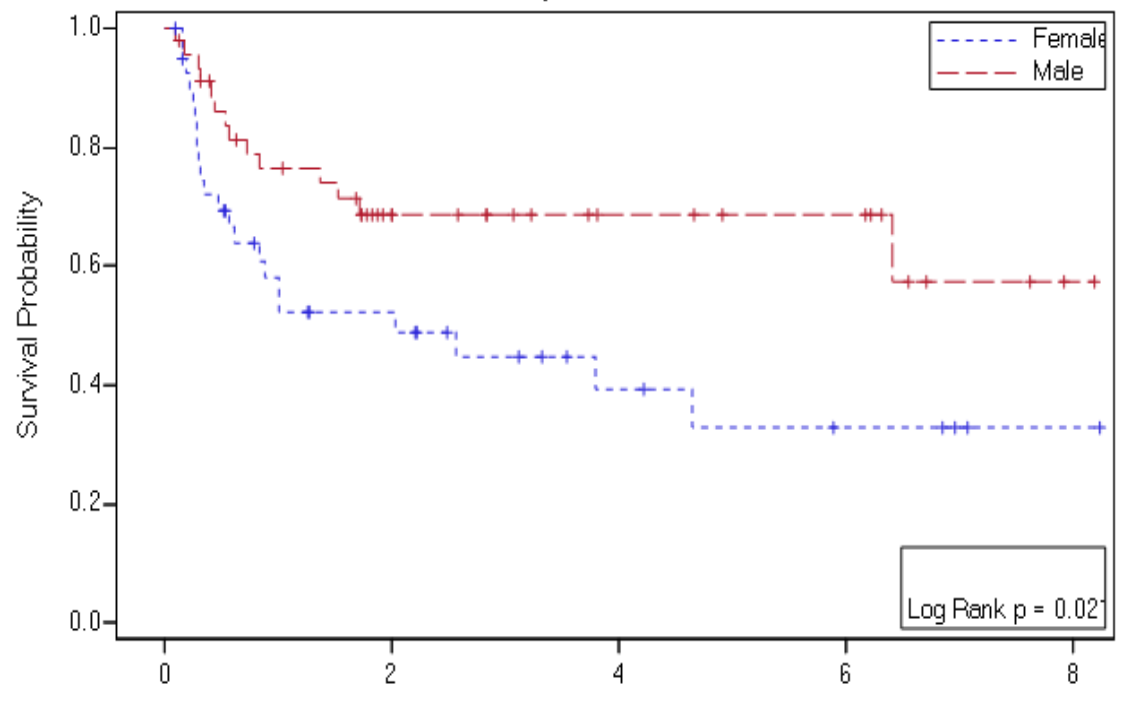

Figure 3. RFS according to gender

significant for survival outcomes, with only a trend toward improved EFS in those who received two or less salvage chemotherapy lines.Our results are comparable with what reported in the litreture.

\section{References}

1. Specht L, Gray RG, Clarke MJ, Peto R (1998) Influence of more extensive radiotherapy and adjuvant chemotherapy on long-term outcome of early-stage Hodgkin's disease: a meta-analysis of 23 randomized trials involving 3,888 patients. International Hodgkin's Disease Collaborative Group. J Clin Oncol 16: 830-843.

2. Oza AM, Ganesan TS, Leahy M, Gregory W, Lim J, et al. (1993) Patterns of survival in patients with Hodgkin's disease: long follow up in a single centre. Ann Oncol 4: 385-392. [Crossref]

3. Canellos GP, Anderson JR, Propert KJ, Nissen N, Cooper MR, et al. (1992) Chemotherapy of advanced Hodgkin's disease with MOPP, ABVD, or MOPP alternating with ABVD. N Engl J Med 327: 1478-1484

4. Somers R, Carde P, Henry-Amar M, Tarayre M, Thomas J, et al. (1994) A randomized study in stage IIIB and IV Hodgkin's disease comparing eight courses of MOPP versus an alteration of MOPP with ABVD: a European Organization for Research and Treatment of Cancer Lymphoma Cooperative Group and Groupe Pierre-et-Marie-Curie controlled clinical trial. J Clin Oncol 12: 279-287.

5. Radford JA, Crowther D, Rohatiner AZ, Ryder WD, Gupta RK, et al. (1995) Results of a randomized trial comparing MVPP chemotherapy with a hybrid regimen, ChlVPP/ EVA, in the initial treatment of Hodgkin's disease. J Clin Oncol 13: 2379-2385.

6. Viviani S, Bonadonna G, Santoro A, Bonfante V, Zanini M, et al. (1996) Alternating versus hybrid MOPP and ABVD combinations in advanced Hodgkin's disease: tenyear results. J Clin Oncol 14: 1421-1430. [Crossref]

7. Bierman PJ, Bagin RG, Jagannath S, Vose JM, Spitzer G, et al. (1993) High dose chemotherapy followed by autologous hematopoietic rescue in Hodgkin's disease: Long term follow-up in 128 patients. Ann Oncol 4: 767-773.

8. Desch CE, Lasala MR, Smith TJ, Hillner BE (1992) The optimal timing of autologous bone marrow transplantation in Hodgkin's disease patients after a chemotherapy relapse. J Clin Oncol 10: 200-209.

9. Chopra R, McMillan AK, Linch DC, Yuklea S, Taghipour G, et al. (1993) The place of high-dose BEAM therapy and autologous bone marrow transplantation in poor-risk Hodgkin's disease. A single-center eight-year study of 155 patients. Blood 81: 1137-1145.

10. Yahalom J, Gulati S, Shank B, Clarkson B, Fuks Z (1989) Total lymphoid irradiation, high-dose chemotherapy and autologous bone marrow transplantation for chemotherapy-resistant Hodgkin's disease. Int J Radiat Oncol Biol Phys 17: 915-922.

11. Reece DE, Connors JM, Spinelli JJ, Barnett MJ, Fairey RN, et al. (1994) Intensive therapy with cyclophosphamide, carmustine, etoposide+/-cisplatin, and autologous bone marrow transplantation for Hodgkin's disease in first relapse after combination chemotherapy. Blood 83: 1193-1199.
12. Nademanee A, O’Donnell MR, Snyder DS, Schmidt GM, Parker PM, et al. High-dose chemotherapy with or without total body irradiation followed by autologous bone marrow and/or peripheral blood stem cell transplantation for patients with relapsed and refractory Hodgkin's disease: results in 85 patients with analysis of prognostic factors. Blood 85: 1381-1390.

13. Yuen AR, Rosenberg SA, Hoppe RT, Halpern JD, Horning SJ (1997) Comparison between conventional salvage therapy and high-dose therapy with autografting for recurrent or refractory Hodgkin's disease. Blood 89: 814-822.

14. Horning SJ, Chao NJ, Negrin RS, Hoppe RT, Long GD, et al. (1997) High-dose therapy and autologous hematopoietic progenitor cell transplantation for recurrent or refractory Hodgkin's disease: analysis of the Stanford University results and prognostic indices. Blood 89: 801-813.

15. Strehl J, Mey U, Glasmacher A, Djulbegovic B, Mayr C, et al, (2003) High-dose chemotherapy followed by autologous stem cell transplantation as first-line therapy in aggressive non-Hodgkin's lymphoma: a meta-analysis. Haematologica 88: 1304-1315.

16. Lavoie JC, Connors JM, Phillips GL, Reece DE, Barnett MJ, et al. (2005) High-dose chemotherapy and autologous stem cell transplantation for primary refractory or relapsed Hodgkin lymphoma: long-term outcome in the first 100 patients treated in Vancouver. Blood 106: 1473-1478.

17. Burns LJ, Daniels KA, McGlave PB, Miller WJ, Ramsay NK, et al. (1995) Autologous stem cell transplantation for refractory and relapsed Hodgkin's disease: factors predictive of prolonged survival. Bone Marrow Transplant 16: 13-18.

18. Linch DC, Winfield D, Goldstone AH, et al. Dose intensification with autologous bonemarrow transplantation in relapsed and resistant Hodgkin's disease: Results of a BNLI randomized trial. Lancet 341: 1051-1054.

19. Schmitz N, Pfistner B, Sextro M, Sieber M, Carella AM, et al. (2002) Aggressive conventional chemotherapy compared with high-dose chemotherapy with autologous haemopoietic stem-cell transplantation for relapsed chemosensitive Hodgkin's disease: a randomised trial. Lancet 359: 2065-2071.

20. O’Brien ME, Milan S, Cunningham D, Jones AL, Nicolson M, et al. (1996) High-dose chemotherapy and autologous bone marrow transplant in relapsed Hodgkin's disease-a pragmatic prognostic index. Br J Cancer 73: 1272.

21. Jagannath S, Armitage JO, Dicke KA, Tucker SL, Velasquez WS, et al. (1989) Prognostic factors for response and survival after high-dose cyclophosphamide, carmustine, and etoposide with autologous bone marrow transplantation for relapsed Hodgkin's disease. J Clin Oncol 7: 179-185.

22. Crump M, Smith AM, Brandwein J, Couture F, Sherret H, et al. (1993) High-dose etoposide and melphalan, and autologous bone marrow transplantation for patients with advanced Hodgkin's disease: importance of disease status at transplant. J Clin Oncol 11: 704-711.

23. Peggs KS, Hunter A, Chopra R, Parker A, Mahendra P, et al. (2005) Clinical evidence of a graft-versus-Hodgkin's-lymphoma effect after reduced-intensity allogeneic transplantation. The Lancet 365: 1934-1941. 
Khalid H (2018) High-dose therapy and autologous hematopoietic progenitor cells transplantation for relapsed or refractory hodgkin lymphoma: a follow up analysis of king hussein cancer center,results and prognostic variables

24. Foyil KV, Bartlett NL (2011) Brentuximab vedotin for the treatment of CD30+ lymphomas. Immunotherapy 3: 475-485.

25. Chen R, Gopal AK, Smith SE, Ansell SM, Rosenblatt JD, et al. (2016) Five-year survival and durability results of brentuximab vedotin in patients with relapsed or refractory Hodgkin lymphoma. Blood 1: blood-2016.

26. Moskowitz CH, Nademanee A, Masszi T, Agura E, Holowiecki J, et al. (2015) Brentuximab vedotin as consolidation therapy after autologous stem-cell transplantation in patients with Hodgkin's lymphoma at risk of relapse or progression (AETHERA): a randomised, doubleblind, placebo-controlled, phase 3 trial. Lancet 385: 1853-1862. [Crossref]

27. Cheson BD, Fisher RI, Barrington SF, Cavalli F, Schwartz LH, et al. (2014) Recommendations for initial evaluation, staging, and response assessment of Hodgkin and non-Hodgkin lymphoma: the Lugano classification. J Clin Oncol 32: 3059.
28. Assouline S, Meyer RM, Infante-Rivard C, Connors JM, Belch A, et al. (2007) Development of adapted RECIST criteria to assess response in lymphoma and their comparison to the International Workshop Criteria. Leuk Lymphoma 48: 513-520.

29. Chen R, Palmer JM, Thomas SH, Tsai NC, Farol L, et al. (2012) Brentuximabvedotin enables successful reduced-intensity allogeneic hematopoietic cell transplantation in patients with relapsed or refractory Hodgkin lymphoma. Blood 119: 6379-6381.

30. Chen R, Zinzani PL, Fanale MA, Armand P, Johnson NA, et al. (2017) Phase II Study of the Efficacy and Safety of Pembrolizumab for Relapsed/Refractory Classic Hodgkin Lymphoma. J Clin Oncol 35: 2125-2132.

31. Younes A, Santoro A, Shipp M, Zinzani PL, Timmerman JM, et al. (2016) Nivolumab for classical Hodgkin's lymphoma after failure of both autologous stem-cell transplantation and brentuximab vedotin: a multicentre, multicohort, single-arm phase 2 trial. Lancet Oncol 17: 1283-1294.

Copyright: $\odot 2018$ Khalid H. This is an open-access article distributed under the terms of the Creative Commons Attribution License, which permits unrestricted use, distribution, and reproduction in any medium, provided the original author and source are credited. 